\title{
What we have learned from urinary bladder cancer models
}

\author{
Carina Bernardo ${ }^{1,2}$, Céu Costa ${ }^{1,4}$, Carlos Palmeira ${ }^{1,3,4}$, Rosário Pinto-Leite ${ }^{1,5}$, Paula Oliveira ${ }^{6}$, Rui Freitas \\ Francisco Amado ${ }^{2}$, Lúcio L. Santos ${ }^{1,4,8}$ \\ ${ }^{I}$ Experimental Pathology and Therapeutics Group-Research Center, Portuguese Oncology Institute-Porto (IPO-Porto), Rua Dr. António Bernardino \\ de Almeida, 4200-072 Porto, Portugal. \\ ${ }^{2}$ Mass Spectrometry Group, QOPNA, Department of Chemistry, University of Aveiro, Campus Universitário de Santiago, 3810-193 Aveiro, Portugal. \\ ${ }^{3}$ Department of Immunology, Portuguese Oncology Institute-Porto (IPO-Porto), Rua Dr. António Bernardino de Almeida, $4200-072$ Porto, Portugal. \\ ${ }^{4}$ School of Health Sciences, Fernando Pessoa University, 4249-004 Porto, Portugal. \\ ${ }^{5}$ Genetic Service, Cytogenetic Laboratory, Hospital Center of Trás-os-Montes e Alto Douro, 5000-508 Vila Real, Portugal. \\ ${ }^{6}$ Department of Veterinary Sciences, CITAB, University of Trás-os-Montes e Alto Douro, 5001-801 Vila Real, Portugal. \\ ${ }^{7}$ Department of Urology, Portuguese Oncology Institute-Porto (IPO-Porto), Rua Dr. António Bernardino de Almeida, $4200-072$ Porto, Portugal. \\ ${ }^{8}$ Department of Surgical Oncology, Portuguese Oncology Institute-Porto (IPO-Porto), Rua Dr. António Bernardino de Almeida, $4200-072$ Porto, \\ Portugal.
}

Correspondence to: Dr. Lúcio L. Santos, Portuguese Oncology Institute-Porto (IPO-Porto), Rua Dr. António Bernardino de Almeida, $4200-072$ Porto, Portugal. E-mail: 1larasantos@gmail.com

\section{A B S T R A C T}

Urinary bladder cancer (UBC) is a heterogeneous disease with highly variable clinical outcomes and responses to chemotherapy. Despite some advances in the molecular understanding of UBC, this knowledge still has not been translated to the clinic in terms of improvements in the prognosis and treatment of patients. Suitable urinary bladder tumor models representative of the human disease in terms of histology and behavior are needed to study factors involved in tumor initiation, progression and metastasis. Further, accurate model systems would facilitate identification of new therapeutic targets and predictive markers that could lead to optimization of existing therapies and development of new ones. Many established cancer cell lines derived from human urinary bladder tumors representing different grades and stages have been used as experimental models for UBC study. These cell lines reflect some of the genetic and morphologic alterations observed in human urothelial carcinoma and serve as simplified models to study the behavior of cancer cells in vitro. However, their translational potential is limited due to the artificial conditions, in which the cells are maintained, grown and tested. Animal models offer a more complex and realistic model for the establishment, development, and progression of tumors as well as to evaluate new therapeutic approaches. Over the years, the authors' group has worked with several UBC cell lines, established and characterized chemically induced UBC models, and patient-derived xenografts models. In this study, the authors will provide a summary of the UBC models developed by their group, analyze their translational potential and weaknesses, and define areas that remain to be explored.

Key words: Animal models; cell lines; tumor behavior; urothelial bladder cancer; xenografts

\section{INTRODUCTION}

Urinary bladder cancer (UBC) is a heterogeneous disease in terms of histopathology and clinical behavior. Around $70 \%$ of the patients are diagnosed with non-muscle-invasive bladder cancer (NMIBC) that often recur and, in about 10$30 \%$ of the cases progress to invasive disease despite local therapy. The remaining 30\% are muscle-invasive bladder cancer (MIBC) at presentation and are associated with high risk of metastasis and progression even after radical surgery and systemic treatment. ${ }^{[1]}$ The necessity of lifelong

\begin{tabular}{|l|l|}
\hline \multicolumn{3}{|c|}{ Access this article online } \\
\hline Quick Response Code: & Website: \\
\hline www.jcmtjournal.com & \\
\hline
\end{tabular}

urveillance, repeated relapses, and chemoresistance makes UBC the malignancy with the highest lifetime treatment cost per patient. ${ }^{[2]}$ Patient treatment and surveillance are typically based on tumor histopathological features, such as histologic type, differentiation degree and anatomical extent of the disease. However, it is still challenging to predict the risk of recurrence and progression for individual patients and to identify which patients will significantly benefit from adjuvant and/or neoadjuvant chemotherapy.

This is an open access article distributed under the terms of the Creative Commons Attribution-NonCommercial-ShareAlike 3.0 License, which allows others to remix, tweak, and build upon the work non-commercially, as long as the author is credited and the new creations are licensed under the identical terms.

For reprints contact: service@oaepublish.com

How to cite this article: Bernardo C, Costa C, Palmeira C, Pinto-Leite R, Oliveira $\mathrm{P}$, Freitas $\mathrm{R}$, Amado $\mathrm{F}$, Santos LL. What we have learned from urinary bladder cancer models. J Cancer Metastasis Treat 2016;2:51-8.

Received: 22-07-2015; Accepted: 02-11-2015. 
Recently, several candidate molecular biomarkers have been discovered and could be used to subdivide urinary bladder tumors in clinically relevant subsets, aiding the prognosis, and treatment selection for patients. ${ }^{[3]}$ Further analytical and clinical validation is required to integrate these markers into the clinical practice.

Several risk factors and genetic pathways have been implicated in the development of UBC. Low grade, noninvasive tumors are associated with fibroblast growth factor receptor 3 (FGFR3) and Harvey rat sarcoma viral oncogene homolog (HRAS) overexpression and/or mutations whereas carcinoma in situ (CIS) and high-grade/invasive UBC are associated with tumor protein p53 (TP53), retinoblastoma 1 (RB1), and phosphatase and tensin homolog (PTEN) mutations and/or loss. ${ }^{[4]}$ Chemical and environmental exposure including aromatic amides, aniline dyes, nitrites and nitrates, and tobacco smoking as well as frequent cystitis and Schistosoma haematobium infections are also associated with UBC etiology. ${ }^{[5]}$

Malignant UBC consists of heterogeneous mass of interconnected cells containing tumor cells in different phases of the cell cycle, cancer stem cells subpopulations, supporting stromal cells and vasculature. Several tumor models have been used in basic science studies and clinical trials to increase our understanding of molecular mechanisms underlying tumor initiation, progression, metastasis and chemoresistance; yet none of these models can adequately mimic the clonal origin, histopathology, progression, and clinical behavior of human tumors. Therefore, a combinatorial approach based on multiple model systems studying specific aspects of this highly complex disease is required. Several models have been used in the study of UBC, ranging from cell lines (including cancer cell lines from human or non-human origin, immortalized and transformed cells, and grown in monolayer or three-dimensional systems) to animal models (including carcinogen-induced tumor models, xenografts, and genetically engineered mice). Here, we discuss the translational potential and applications of these models with particular emphasis on chemically induced UBC models, patient-derived xenografts (PDXs) models, and human bladder cancer cell lines.

\section{CHEMICALLY INDUCED UBC}

Chemically induced bladder cancer models induced by organo-specific bladder carcinogens were initially explored in the 1960s and were of the first models used to evaluate chemotherapy for UBC. . $^{[6,7]}$ In these models, carcinogenesis of the urothelium occurs after repeated exposure to carcinogens such as N-butyl-N(4-hydroxybutyl) nitrosamine (BBN), N-[4-(5-nitro-2furyl)-2-thiazolyl]-formamide (FANFT), and N-methyl$\mathrm{N}$-nitrosourea mimicking the environmental exposure known to be the leading cause of bladder cancer in humans. The carcinogens can be delivered systemically, by gavage or in the drinking water, or locally, by injection or via instillation. The tumor subtype and the time needed for tumorigenesis depend on the carcinogen used, animal species and strains and the treatment regimen. Because these models use immunocompetent animals and are highly reproducible, they can be used to study the mechanisms involved in pathogenesis of bladder cancer and are suitable for studies on interactions between host immune system and the tumor. In addition, several rodent bladder cancer cell lines derived from carcinogen-induced bladder tumors were established and made available for in vitro and in vivo studies. These include rat bladder tumor cell lines such as Nara bladder tumor II and AY-27 derived from BBN-induced bladder tumors in Wistar rats, and Fischer 344 rats exposed to FANFT, respectively. The murine bladder tumor-2 murine bladder cancer cell line, derived from an FANFT-induced bladder tumor in $\mathrm{C} 3 \mathrm{H}$ mice, has also been widely used. ${ }^{[8-10]}$ Rodents are exceptionally suited for these types of studies because rats and mice do not develop spontaneous urinary bladder tumors under normal conditions. ${ }^{[11]}$ The occurrence of non-neoplastic urothelial lesions, such as inflammation and hyperplasia, is also uncommon in these species. ${ }^{[12]}$

In our studies, $\mathrm{C} 3 \mathrm{H} / \mathrm{He}$ mice were exposed to $\mathrm{BBN}$, a complete genotoxic carcinogen metabolically derived from a compound found in tobacco smoke. Exposure to $\mathrm{BBN}$ in the drinking water induced the development of hyperplasia, dysplasia, low and high-grade papillary UBC, CIS, and MIBC in the urothelium of exposed rodents. ${ }^{[13]}$ The grade of cell atypia and extent of tumor invasion increased with increasing doses of carcinogen and extended period of exposure. ${ }^{[12]}$ Similar exposure to $\mathrm{BBN}$ resulted in papillary tumors in Fischer 344 rats. ${ }^{[13]}$ The broad spectrum of lesions mimics the major pathogenic mechanisms found in human urinary bladder carcinogenesis: pre-neoplastic lesions occur before in situ and muscle-invasive tumors, following different genetic pathways. These lesions are characterized by 3 different variables with recognized relationship to the natural history of UBC and patient outcome as DNA content, p53 alterations, and proliferative index measured by Ki-67 protein expression. DNA ploidy was evaluated by calculating the $5 \mathrm{c}$ exceeding rate, defined as the percentage of cells with values above $5 \mathrm{n}$. Alterations in these markers were detected even in non-malignant histological lesions but were more frequent in urothelial tumors with higher malignant and aggressive potential namely CIS, high-grade papillary and muscle-invasive tumors as shown in Figure 1. ${ }^{[13]}$ This abnormal biological profile represents a high level of genetic instability underlying the urothelium carcinogenesis process. This phenomenon is well known in human UBC, especially when CIS is present. The CIS surrounding normal-appearing urothelium shows a high frequency of abnormal DNA content, p53 mutated protein expression, and a high proliferative status. ${ }^{[11,14]}$ 


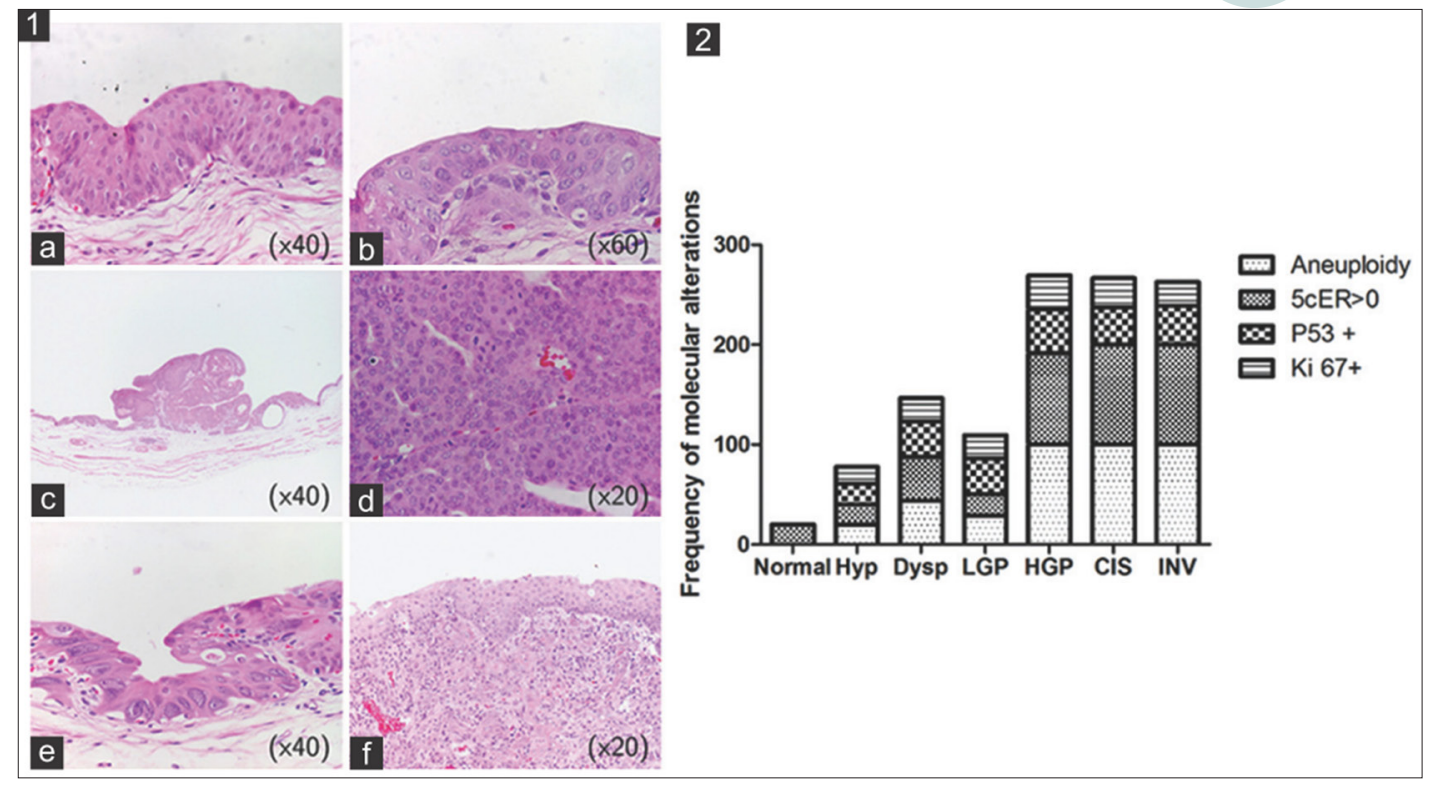

Figure 1: Urological lesions identified in rats exposed to BBN. (1) Hematoxylin and eosin stain; (2) respective molecular alterations. a: Hyp; b: Dysp; c: LGP urothelial carcinoma; d: HGP urothelial carcinoma; e: CIS; f: INV. BBN: N-butyl-N-(4-hydroxybutyl) nitrosamine; Hyp: hyperplasia; Dysp: dysplasia; LGP: low grade papillary; HGP: high grade papillary; CIS: carcinoma in situ; INV: invasive urothelial carcinoma; 5cER: 5c exceeding rate

Our studies revealed histopathological and biological similarities between the rodent urothelium carcinogenesis process and the corresponding process in humans. ${ }^{[11]}$ The more aggressive lesions identified in rats showed a higher rate of DNA aneuploidy, p53 immunoexpression, and Ki-67 labeling index. This biological profile was also observed in early stage human tumors, suggesting that the rat model is more suitable to study the papillary pathway or NMIBC. These results are in agreement with William et al., who purport that rodent (rat) tumors provide an accurate mechanistic model for the study of genes putatively involved in invasive and metastatic UBC. ${ }^{[15]}$ The main limitations of these models are the cost, long experimental protocol and the difficulty to monitor UBC development during the experimental protocol.

\section{PATIENT-DERIVED UBC XENOGRAFT MODEL}

PDX tumor models are primarily obtained by implanting human-derived tumor cells into immunocompromised mice. The tumors growing in these animals derive directly from patient tumor samples with minimal manipulation and recapitulate the biological characteristics of the human tumor of origin. Figure 2 presents a schematic representation of a study design to establish a direct tumor xenograft model from human samples. The expansion cohort enables the amplification of tumor tissue to establish a treatment cohort.

Tumors grown in these mice can also be stored by slow freezing in appropriate medium to replicate the model later. These models retain the cellular structure and molecular markers of the original tumors and have high predictive power ${ }^{[16-18]}$ PDX are suitable to evaluate the effectiveness of anticancer drugs, providing not only an investigational platform but a potential therapeutic decision-making tool based on the expression profile of individual tumors and their responsiveness to individual therapies. ${ }^{[19]}$

As a proof of concept, our group established and characterized a patient-derived UBC xenograft model to evaluate tumors expressing translational modifications of cell surface proteins in vivo. A freshly collected sample of human MIBC was fragmented and subcutaneously engrafted into male nude mice and expanded until the third passage. Histology and immunohistochemistry of tumor markers [p53, p63, Ki-67, CK20 and sialyl-Tn (sTn)] were used to evaluate tumor phenotype maintenance. ${ }^{[20]}$ According to our results, the model recapitulated the histological and molecular nature of the primary tumor, including the expression of the cell-surface antigen sTn, a protein post-translational modification associated with motility and invasive capacity of UBC cells. ${ }^{[2]}$

The main limitations of this model are the long latency period before tumor growth begins and low take rate, especially in the first passage. The stroma and blood supply are provided by the host, and the tumor is not growing in the organ of origin. The artificial tumor microenvironment may explain the rare occurrence of tumor metastasis observed in these subcutaneous models. ${ }^{[22]}$ The absence of host immune system is also an important factor to consider, as it influences tumor behavior. ${ }^{[23]}$ We were unsuccessful in establishing PDX in nude rats with none of the 7 implanted tumors grafting during a 12 months period. The explanation for this results remains to be elucidated. 


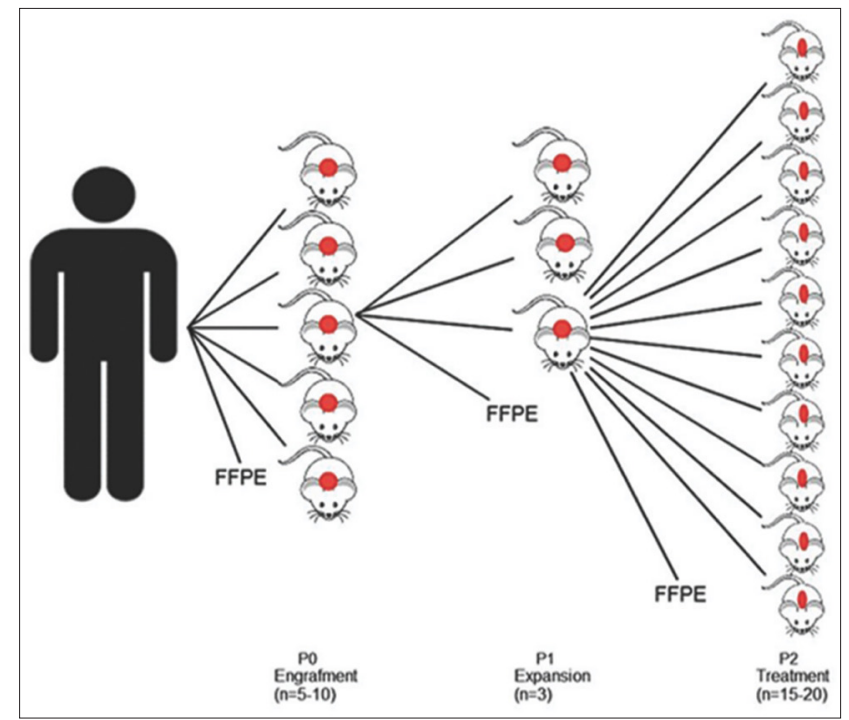

Figure 2: Schematic representation of the study design to establish a patient-derived tumor xenograft model. The original tumor and tumors grown in mice can be analyzed and compared using fresh or Formalin-fixed, paraffin-embedded tumor samples for histology and immunoexpression of specific markers. FFPE: Formalin-fixed, paraffin-embedded

Subrenal capsule xenografting of primary bladder tumor in mice has been recently described with higher tumor take rates and retention of the genetic and morphological characteristics of the primary tumor. ${ }^{[2]}$ Both subcutaneous and subcapsular renal sites are not the orthotopic location for bladder cancer growth; however, the latter seems to be a more favorable environment for PDX survival and growth as is also observed for other cancer. ${ }^{[25,26]}$ The use of PDXs mice is feasible and allows a higher predictive power than other animal models..$^{[27,28]}$ Because of this, PDX will be an increasingly valuable tool in the evaluation of human tumor response to traditional and new chemotherapeutic drugs.

\section{UBC CELL LINES}

Cell lines established from tumors and adapted to proliferate in culture have been extensively used in cancer research and their use has significantly improved our knowledge of cancer biology. Cancer cell lines have an important role in the study of the biological effects of genetic alterations in different tumor subtypes, in the identification and characterization of genes involved in cancer initiation and progression, and drug testing. In vitro assays using panels of cell lines are used as first line models in the preclinical development of new drugs to discover, validate, and evaluate the potential of new therapeutic agents. ${ }^{[29]}$ Gene expression can be manipulated in cell culture to introduce gain- or lossof-function mutations to evaluate the biological effect on cell survival and proliferation, both in vitro and in vivo through the use of xenografts or syngeneic models. For more than a half-century, tumor cell lines served as a foundation for cancer research since they are easy to use and cost-effective. Within the bladder cancer field, available cell lines represent different bladder cancer subtypes and varying degrees of genetic complexity depending on the sample of origin. However, continuous passages and culture of cells in vitro selects the cells better adapted to in vitro culture, reducing the heterogeneity, and promoting the acquisition of new mutations. Several human bladder cancer cell lines have been established and used over the years for multiple purposes. As a result of these studies, genomic and pharmacological profiles of 28 human bladder cancer cell lines are now available in the Cancer Cell Line Encyclopedia (https://www. broadinstitute.org/software/cprg/?q=node/11). ${ }^{[30]}$

Our in vitro studies on UBC were based on three different human cancer cell lines: 5637, T24 and HT1376. These cell lines have been widely used to evaluate efficacy of anticancer drugs. Although significant heterogeneity and complexity were detected between them, their genomic profiles exhibited a similar pattern to human UBC. ${ }^{[31]}$ The NMIBC cell line 5637 and the two MIBC cell lines T24 and HT1376 cover the most frequent subtypes of UBC; T24 represents an FGFR3/Cyclin D1 subtype, while 5637 and HT1376 represent the E2F3/RB1 pathway mutational profile, with the former representing a less aggressive phenotype and the later bearing more invasive and metastatic properties. ${ }^{[31]}$ Figure 3 shows the karyogram of HT1376 cell line that presented a near-tetraploid karyotype with complex arrangements in several chromosomes.

We have used the cell lines 5637, T24, and HT1376 to evaluate the effect of everolimus and temsirolimus [sirolimus analogs and mammalian target of rapamycin (mTOR) inhibitors] in UBC cells. mTOR signaling was found to play an important role in cell growth, survival, proliferation, and angiogenesis in eukaryotic cells and its dysregulation was detected in many cancer, including in $\mathrm{UBC}$, where it is believed to have potential for prognostic information and targeted therapy. ${ }^{[32-34]}$ Therapies targeting mTOR are already used in the clinics to treat renal cell carcinoma and mantle cell lymphoma. ${ }^{[35]}$ Their potential application to the treatment of other cancer is studied, particularly in combinational strategies, to overcome resistance and enhance efficacy of standard therapies. According to our studies, sirolimus analogs exert a slight interference on proliferation, apoptosis, and autophagy in these cancer cell lines. The NMIBC cell line 5637 was the most sensitive to mTOR inhibitor treatment alone. ${ }^{[36,37]}$ Considering other preclinical studies where sensitivity to mTOR inhibitors has been associated with PTEN loss, ${ }^{[38]}$ we expected that the UBC cell lines 5637 and HT1376 (both of which harbor deletion of PTEN), would respond well to sirolimus analogs. However, only 5637 was sensitive to monotherapy. More recently, in patients with MIBC treated with everolimus, PTEN loss was associated with resistance to treatment with the unhampered feedback loop driving PI3K/Akt activation suggesting 


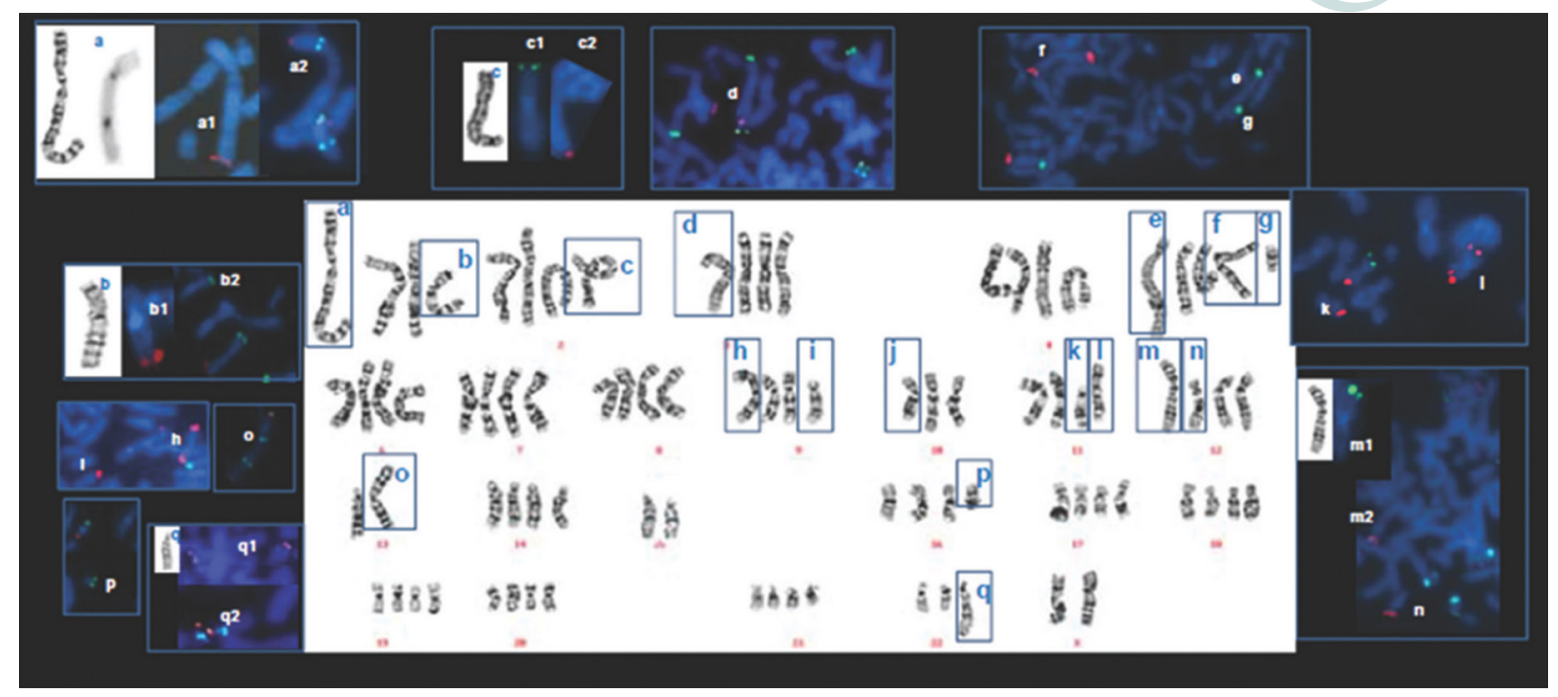

Figure 3: Karyogram of HT1376 with GTL banding. The chromosomes with changes are marked within square with letters that represent partial metaphases with GTL and FISH subtelomeric probes. GTL: giemsa trypsin leishman banding; FISH: fluorescent in situ hibridization

that the use of both PI3K and mTOR inhibitors would be beneficial in these cases. ${ }^{[39]}$ We further evaluated the combined effect of mTOR inhibitors with gemcitabine and cisplatin, which are currently used in the treatment of MIBC. The combined therapy resulted in enhanced inhibition of cell proliferation, increased apoptosis and autophagy, especially in 5637 and HT1376 cell lines, when compared with gemcitabine or cisplatin alone. In contrast, in the T24 cell line, the addition of everolimus or temsirolimus to cisplatin did not increase the efficacy of the latter one but, when combined to gemcitabine resulted in enhanced cell proliferation inhibition. ${ }^{[40-43]}$ This evidence supports the role of complex tumor signaling pathways in tumor behavior and response to chemotherapy and highlights the diverse and sometimes controversial results observed in preclinical studies.

To some extent, the cell lines used in our investigation reflect the tumor heterogeneity and its response to anticancer drugs. Knowing the limitations of this study material, the use of cell lines can be a very important starting point, indicating new research opportunities. However, evidence from in vitro studies must be further confirmed using more realistic and complex models such as xenografts.

In addition to in vitro assays, human cell lines have been widely used to establish xenograft models in mice. In this model, tumor cells are implanted either under the skin (heterotopic) or in the bladder (orthotopic). In orthotopic models, the tumor arises within the bladder of the recipient host allowing the study of tumor cells behavior in the normal host tissue microenvironment. Single cell suspensions of bladder cancer cell lines can be inoculated by intravesical instillation or direct injection into the bladder wall to establish xenografts or syngeneic models, if using human cell lines or mouse/ rat cell lines in the corresponding background strain, respectively. ${ }^{[10,44]}$ To achieve reliable tumor take after transurethral implantation of tumor cells, the host bladder is usually submitted to catheterization with chemical pre-treatment or mechanical traumatization. Although widely used, these methods are often associated with adverse reactions in some study animals and can lead to uncontrolled tumor growth in adjacent organs. On the other hand, the injection of tumor cells into the bladder wall frequently relies on laparotomy and mobilization of the bladder, also a morbidity-associated procedure. More recently, ultrasound guided percutaneous implantation of cells between the urothelium and lamina propria have been reported with the benefit of accurate cell delivery and a minimally invasive procedure. ${ }^{[45]}$ Bladder palpation and urine inspection are the initial approaches to identify growing tumors, followed by imaging techniques such as ultrasound, magnetic resonance imaging and bioluminescence. ${ }^{[45,46]}$ Inclusion of fluorescent or luciferase reporter genes in tumor cells prior to implantation enables in vivo imaging of tumors and metastases, and this method has been validated in mouse orthotopic models with promising results. ${ }^{[47]}$

\section{CONCLUSION}

UBC is a complex disease with both genetic and environmental factors playing a role in tumor initiation, progression, and metastasis. In addition to the models used by our group, many more have been developed and are available to study the molecular biology, behavior, and chemosensitivity of UBC.

Most murine orthotopic UBC models can be obtained by three ways such as induced by a chemical carcinogen, implantation of human UBC cells in immunocompromised mice, or implantation of murine UBC cells in immunocompetent mice (allograft or syngeneic models). The model characteristics will depend on the site of 
tumor cell implantation and the origin of implanted cells: traditional cell lines, primary cell culture, patient-derived tumor fragments, or tumor cells suspension. These factors influence tumor heterogeneity and the ability to model human tumor identity and behavior. ${ }^{[48]}$ Moreover, a greater understanding of UBC molecular biology has enabled the development of genetically engineered mouse models that recapitulate genetic abnormalities of human tumors and allow the study of individually altered genes in tumor behavior and response to therapy in vivo. These models are created by knock out or knock in of genes involved in transformation or malignancy such as HRAS, EGFR, TP53, PTEN, or RB as reviewed elsewhere. ${ }^{[49]}$ These models provide a useful platform to study genetic events associated with tumor development and progression without losing tumor microenvironment and the immune system of the host. However, they can fail to reproduce tumor heterogeneity and the genetic complexity of human tumors, which influence tumor progression and metastasis. More recently, animal models with functional immune systems are gaining attention as a platform to test emerging immunotherapies such as anti-programmed death ligand-1. ${ }^{[50]}$

Despite the numerous existing UBC models, some mechanisms underlying the pathophysiology of these tumors remains unknown, such as in the case of Schistosome-related UBC. This is mainly due to the lack of a tractable animal model. Hsieh et al. have developed a mouse model of $S$. haematobium urinary tract infection after microinjection of purified $S$. haematobium eggs into the urothelial bladder wall. ${ }^{[51]}$ This model recapitulates several aspects of human urothelial schistosomiasis however, the development of infection-associated UBC was not reported and remains to be explored.

\section{Financial support and sponsorship}

CB thanks the FCT (Fundação para a Ciência e a Tecnologia) for the PhD scholarship SFRH/ BD/80855/2011.

\section{Conflicts of interest}

There are no conflicts of interest.

\section{REFERENCES}

1. Witjes JA, Compérat E, Cowan NC, De Santis M, Gakis G, Lebret T, Ribal MJ, Van der Heijden AG, Sherif A. European Association of Urology. EAU guidelines on muscle-invasive and metastatic bladder cancer: summary of the 2013 guidelines. Eur Urol 2014;65:778-92.

2. Sievert KD, Amend B, Nagele U, Schilling D, Bedke J, Horstmann M, Hennenlotter J, Kruck S, Stenzl A. Economic aspects of bladder cancer: what are the benefits and costs? World J Urol 2009;27:295-300.

3. Netto GJ. Molecular biomarkers in urothelial carcinoma of the bladder: are we there yet? Nat Rev Urol 2012;9:41-51. Goebell PJ, Knowles MA. Bladder cancer or bladder cancers? enetically distinct malignant conditions of the urothelium. Urol Oncol Semin Orig Investig 2010;28:409-28.
4. Goebell PJ, Knowles MA. Bladder cancer or bladder cancers? Genetically distinct malignant conditions of the urothelium. Urol Oncol Semin Orig Investig 2010;28:409-28.

5. Burger M, Catto JW, Dalbagni G, Grossman HB, Herr H, Karakiewicz P, Kassouf W, Kiemeney LA, La Vecchia C, Shariat S, Lotan Y. Epidemiology and risk factors of urothelial bladder cancer. Eur Urol 2013;63:234-41.

6. Druckrey H, Preussmann R, Ivankovic S, Schmidt CH, Mennel HD, Stahl KW. Selective induction of bladder cancer in rats by Dibutyl- and N-Butyl-N-butanol (4)-nitrosamine.Z Krebsforsch 1964;66:280-90.

7. Soloway MS. Single and combination chemotherapy for primary murine bladder cancer. Cancer 1975;36:333-40.

8. Toyoshima K, Ito N, Hiasa Y, Kamamoto Y, Makiura S. Tissue culture of urinary bladder tumor induced in a rat by N-Butyl-N-(-4Hydroxybutyl) nitrosamine: establishment of cell line, nara bladder tumor. J Natl Cancer Inst 1971;47:979-85.

9. Xiao Z, McCallum TJ, Brown KM, Miller GG, Halls SB, Parney I, Moore RB. Characterization of a novel transplantable orthotopic rat bladder transitional cell tumour model. Br J Cancer 1999;81:638-46.

10. Chan ES, Patel AR, Smith AK, Klein JB, Thomas AA, Heston WD, Larchian WA. Optimizing orthotopic bladder tumor implantation in a syngeneic mouse model. J Urol 2009;182:2926-31.

11. Palmeira C, Oliveira PA, Lameiras C, Amaro T, Silva VM, Lopes C, Santos L. Biological similarities between murine chemical-induced and natural human bladder carcinogenesis. Oncol Lett 2010;1:373-7.

12. Oliveira PA, Colaço A, De La Cruz P LF, Lopes C. Experimental bladder carcinogenesis-rodent models. ExpOncol 2006;28:2-11.

13. Oliveira PA, Palmeira C, Colaço A, De La Cruz P LF, Lopes C. DNA content analysis, expression of $\mathrm{Ki}-67$ and p53 in rat urothelial lesions induced by N-butyl-N-(4-hydroxybutyl) nitrosamine and treated with mitomycin $\mathrm{C}$ and Bacillus Calmette-Gue'rin. Anticancer Res 2006;26:2995-3004.

14. Dyrskjøt L, Kruhøffer M, Thykjaer T, Marcussen N, Jensen JL, Møller $\mathrm{K}$, Ørntoft TF. Gene expression in the urinary bladder: a common carcinoma in situ gene expression signature exists disregarding histopathological classification. Cancer Res 2004;64:4040-8.

15. Williams PD, Lee JK, Theodorescu D. Molecular credentialing of rodent bladder carcinogenesis models. Neoplasia 2008;10:838-46.

16. Fichtner I, Slisow W, Gill J, Becker M, Elbe B, Hillebrand T, Bibby M. Anticancer drug response and expression of molecular markers in early-passage xenotransplanted colon carcinomas. Eur J Cancer 2004;40:298-307.

17. Rubio-Viqueira B, Hidalgo M. Direct in vivo xenograft tumor model for predicting chemotherapeutic drug response in cancer patients. Clin Pharmacol Ther 2009;85:217-21.

18. Dong X, Guan J, English JC, Flint J, Yee J, Evans K, Murray N, Macaulay C, Ng RT, Gout PW, Lam WL, Laskin J, Ling V, Lam S, Wang Y. Patient-derived first generation xenografts of non-small cell lung cancers: promising tools for predicting drug responses for personalized chemotherapy. Clin Cancer Res 2010;16:1442-51.

19. Hidalgo M, Bruckheimer E, Rajeshkumar NV, Garrido-Laguna I, De Oliveira E, Rubio-Viqueira B, Strawn S, Wick MJ, Martell J, Sidransky D. A pilot clinical study of treatment guided by personalized tumorgrafts in patients with advanced cancer. Mol Cancer Ther 2011;10:1311-6.

20. Bernardo C, Costa C, Amaro T, Gonçalves M, Lopes P, Freitas R, Gärtner F, Amado F, Ferreira JA, Santos L. Patient-derived Sialyl- 
Tn-positive invasive bladder cancer xenografts in nude mice: an exploratory model study. Anticancer Res 2014;34:735-44.

21. Ferreira JA, Videira PA, Lima L, Pereira S, Silva M, Carrascal M, Severino PF, Fernandes E, Almeida A, Costa C, Vitorino R, Amaro T, Oliveira MJ, Reis CA, Dall'Olio F, Amado F, Santos LL. Overexpression of tumour-associated carbohydrate antigen sialyl-Tn in advanced bladder tumours. Mol Oncol 2013;7:719-31.

22. Hoffman RM. Patient-derived orthotopic xenografts: better mimic of metastasis than subcutaneous xenografts. Nat Rev Cancer 2015;15:451-2.

23. Yang L, Carbone DP. Tumor-host immune interactions and dendritic cell dysfunction. Adv Cancer Res 2004;92:13-27.

24. Jäger W, Xue H, Hayashi T, Janssen C, Awrey S, Wyatt AW, Anderson S, Moskalev I, Haegert A, Alshalalfa M, Erho N, Davicioni E, Fazli L, Li E, Collins C, Wang Y, Black PC. Patient-derived bladder cancer xenografts in the preclinical development of novel targeted therapies. Oncotarget 2015;6:21522-32.

25. Cutz JC, Guan J, Bayani J, Yoshimoto M, Xue H, Sutcliffe M, English J, Flint J, LeRiche J, Yee J, Squire JA, Gout PW, Lam S, Wang YZ. Establishment in severe combined immunodeficiency mice of subrenal capsule xenografts and transplantable tumor lines from a variety of primary human lung cancers: potential models for studying tumor progression-related changes. Clin Cancer Res 2006;12:4043-54.

26. Lee CH, Xue H, Sutcliffe M, Sutcliffe M, Gout PW, Huntsman DG, Miller DM, Gilks CB, Wang YZ. Establishment of subrenal capsule xenografts of primary human ovarian tumors in SCID mice: potential models. Gynecol Oncol 2005;96:48-55.

27. Pan C, Zhang H, Tepper CG, Lin TY, Davis RR, Keck J, Ghosh PM, Gill P, Airhart S, Bult C, Gandara DR, Liu E, de Vere White RW. Development and characterization of bladder cancer patient-derived xenografts for molecularly guided targeted therapy. PLoS One 2015;10:e0134346.

28. Park B, Jeong BC, Choi YL, Kwon GY, Lim JE, Seo SI, Jeon SS, Lee HM, Choi HY, Lee KS. Development and characterization of a bladder cancer xenograft model using patient-derived tumor tissue. Cancer Sci 2013;104:1-8.

29. Monks A, Scudiero D, Skehan P, Shoemaker R, Paull K, Vistica D, Hose C, Langley J, Cronise P, Vaigro-Wolff A. Feasibility of a highflux anticancer drug screen using a diverse panel of cultured human tumor cell lines. J Natl Cancer Inst 1991;83:757-66.

30. Barretina J, Caponigro G, Stransky N, Venkatesan K, Margolin AA, Kim S, Wilson CJ, Lehár J, Kryukov GV, Sonkin D, Reddy A, Liu M, Murray L, Berger MF, Monahan JE, Morais P, Meltzer J, Korejwa A, Jané-Valbuena J, Mapa FA, Thibault J, Bric-Furlong E, Raman P, Shipway A, Engels IH, Cheng J, Yu GK, Yu J, Aspesi P Jr, de Silva M, Jagtap K, Jones MD, Wang L, Hatton C, Palescandolo E, Gupta S, Mahan S, Sougnez C, Onofrio RC, Liefeld T, MacConaill L, Winckler W, Reich M, Li N, Mesirov JP, Gabriel SB, Getz G, Ardlie K, Chan V, Myer VE, Weber BL, Porter J, Warmuth M, Finan P, Harris JL, Meyerson M, Golub TR, Morrissey MP, Sellers WR, Schlegel R, Garraway LA. The cancer cell line encyclopedia enables predictive modelling of anticancer drug sensitivity. Nature 2012;483:603-7.

31. Pinto-Leite R, Carreira I, Melo J, Venkatesan K, Margolin AA, Kim S, Wilson CJ, Lehár J, Kryukov GV, Sonkin D, Reddy A, Liu M, Murray L, Berger MF, Monahan JE, Morais P, Meltzer J, Korejwa A, Jané-Valbuena J, Mapa FA, Thibault J, Bric-Furlong E, Raman P, Shipway A, Engels IH, Cheng J, Yu GK, Yu J, Aspesi P Jr, de
Silva M, Jagtap K, Jones MD, Wang L, Hatton C, Palescandolo E, Gupta S, Mahan S, Sougnez C, Onofrio RC, Liefeld T, MacConaill L, Winckler W, Reich M, Li N, Mesirov JP, Gabriel SB, Getz G, Ardlie K, Chan V, Myer VE, Weber BL, Porter J, Warmuth M, Finan P, Harris JL, Meyerson M, Golub TR, Morrissey MP, Sellers WR, Schlegel R, Garraway LA. Genomic characterization of three urinary bladder cancer cell lines: understanding genomic types of urinary bladder cancer. Tumour Biol 2014;35:4599-617.

32. Ching CB, Hansel DE. Expanding therapeutic targets in bladder cancer: the PI3K/Akt/mTOR pathway. Lab Invest 2010;90:1406-14.

33. Netto GJ, Cheng L. Emerging critical role of molecular testing in diagnostic genitourinary pathology. Arch Pathol Lab Med2012;136:372-90.

34. Pal SK, Quinn DI. Differentiating mTOR inhibitors in renal cell carcinoma. Cancer Treat Rev 2013;39:709-19.

35. Ciuffreda L, Di Sanza C, Incani UC, Milella M. The mTOR pathway: a new target in cancer therapy. Curr Cancer Drug Targets 2010;10:484-95.

36. Vasconcelos-Nóbrega C, Pinto-Leite R, Arantes-Rodrigues R, Ferreira R, Brochado P, Cardoso ML, Palmeira C, Salvador A, Guedes-Teixeira CI, Colaço A, Palomino LF, Lopes C, Santos $\mathrm{L}$, Oliveira PA. In vivo and in vitro effects of RAD001 on bladder cancer. Urol Oncol 2013;31:1212-21.

37. Pinto-Leite R, Botelho P, Ribeiro E, Oliveira PA, Santos L. Effect of sirolimus on urinary bladder cancer T24 cell line. J Exp Clin Cancer Res 2009;28:3.

38. Neshat MS, Mellinghoff IK, Tran C, Stiles B, Thomas G, Petersen R, Frost P, Gibbons JJ, Wu H, Sawyers CL. Enhanced sensitivity of PTEN-deficient tumors to inhibition of FRAP/mTOR. Proc Natl Acad Sci U S A 2001;98:10314-9.

39. Seront E, Pinto A, Bouzin C, Bertrand L, Machiels JP, Feron O. PTEN deficiency is associated with reduced sensitivity to mTOR inhibitor in human bladder cancer through the unhampered feedback loop driving PI3K/Akt activation. Br J Cancer 2013;109:1586-92.

40. Pinto-Leite R, Arantes-Rodrigues R, Palmeira C, Colaço B, Lopes C, Colaço A, Costa C, da Silva VM, Oliveira P, Santos L. Everolimus combined with cisplatin has a potential role in treatment of urothelial bladder cancer. Biomed Pharmacother 2013;67:116-21.

41. Pinto-Leite R, Arantes-Rodrigues R, Palmeira C, Gaivão I, Cardoso ML, Colaço A, Santos L, Oliveira P. Everolimus enhances gemcitabine-induced cytotoxicity in bladder-cancer cell lines. $J$ Toxicol Environ Heal Part A 2012;75:788-99.

42. Pinto-Leite R, Arantes-Rodrigues R, Ferreira R, Palmeira C, Colaço A, Moreira da Silva V, Oliveira P, Lara Santos L. Temsirolimus improves cytotoxic efficacy of cisplatin and gemcitabine against urinary bladder cancer cell lines. Urol Oncol Semin Orig Investig 2014;32:41.e11-22.

43. Pinto-Leite R, Arantes-Rodrigues R, Ferreira R, Palmeira C, Oliveira PA, Santos L. Treatment of muscle invasive urinary bladders tumors: a potential role of the mTOR inhibitors. Biomed Aging Pathol 2014;4:169-78.

44. Chan E, Patel A, Heston W, Larchian W. Mouse orthotopic models for bladder cancer research. BJU Int 2009;104:1286-91.

45. Jager W, Moskalev I, Janssen C, Hayashi T, Awrey S, Gust KM, So AI, Zhang K, Fazli L, Li E, Thüroff JW, Lange D, Black PC. Ultrasoundguided intramural inoculation of orthotopic bladder cancer xenografts: a novel high-precision approach. PLoS One 2013;8:e59536. 
46. Black PC, Shetty A, Brown GA, Esparza-Coss E, Metwalli AR, Agarwal PK, McConkey DJ, Hazle JD, Dinney CP. Validating bladder cancer xenograft bioluminescence with magnetic resonance imaging: the significance of hypoxia and necrosis. BJU Int 2010;106:1799-804.

47. Hadaschik BA, Black PC, Sea JC, Metwalli AR, Fazli L, Dinney CP, Gleave ME, So AI. A validated mouse model for orthotopic bladder cancer using transurethral tumour inoculation and bioluminescence imaging. BJU Int 2007;100:1377-84.

48. Voskoglou-Nomikos T, Pater JL, Seymour L. Clinical predictive value of the in vitro cell line, human xenograft, and mouse allograft preclinical cancer models. Clin Cancer Res 2003;9:4227-39.
49. Alunad 1 Sansom OJ Leung HY. Exploring molecular genetics of bladder cancer: lessons learned from mouse models. Dis Model Mech 2012;5:323-32

50. Pilon-Thomas S, Mackay A, Vohra N, Mulé JJ. Blockade of programmed death ligand 1 enhances the therapeutic efficacy of combination immunotherapy against melanoma. $J$ Imrmmol 2010;184:3442-9.

51. Fu CL, Odegaard JI, Herbert DR, Hsieh MH. A novel mouse model of Schistosoma haematobium egg-induced immunopathology. PLoS Pathog 2012;8:el002605. 